\title{
A Life Dedicated to Support a Family Meal: The Women Trisikad Drivers' Story
}

\author{
Adora A. Villaganas \\ Wilma C. Giango \\ Elvisa O. Basubas
}

Gender and Development, Cebu Technological University, Cebu, Philippines

Victor Villaganas

Vice- President for Academic Affairs, Cebu Technological University, Cebu

City, Philippines

doi: 10.19044/esj.2016.v12n17p116 URL:http://dx.doi.org/10.19044/esj.2016.v12n17p116

\begin{abstract}
The study determined the fantasies and aspirations of women trisikad drivers in Cebu City, Philippines. Specifically, the study aimed to: determine the personal profile of women trisikad drivers in Pasil, Taboan, and San Nicolas, Cebu City, examine the factors that influence their lives, extrapolate lived experiences that promote women's decisiveness and access to economic resources. The study utilized a case study design with narrative descriptions of the primary respondents. The data generated were clustered, coded, and metaphorical themes were illuminated. Life of women trisikad drivers was dedicated to support a family meal, being a co-equal with their husbands. Living an impoverished life 'starved like a rat' in order to meet both ends meet. Their assertive fantasies proved that they were normal individuals who felt like: 'a superwoman that finds her way out at the end of the tunnel', empowered and took control over scarce resources, 'a blooming lily under the 49 degrees heat of a tropical summer', struggled poverty, and 'a mother hen protecting their chicks from a gliding skyline hawk', raised an income for children's survival. Their life-changing aspirations included: 'chasing ice castles in the air', never met the normal Cindrella life syndrome, 'buoyant force that makes the boat sail to its final destination, with their husbands as the propeller', gained support by their husbands, and 'newly hibernated amphibians in a hostile ecosystem', despised the strain of gender stereotyping. Their lived experiences characterized in 'painful joy' because of their minimal income, 'serving as an army of ants', chased equally with their male counterparts just to bring food on the table, and 'being the winds beneath their husbands' wings', assured by their husbands' love and protection. Though, their economic status is a 'scratching and pecking
\end{abstract}


condition’, earned typically in day-to-day subsistence with hope.

Keywords: Trisikad, women’s rights, Cinderella syndrome

\section{Introduction}

In a patriarchal society, women are commonly attached to the home as the most strategic; yet a secluded place in the village. A pre-conceived notion of men for women to be protected on the harsh realities in the field, they are destined as homemakers, baby-makers or metaphorically dubbed as 'the light of the family'. They are attached to home industries like needle crafts, embroidery, and weaving. Inocian (2015) rejoins that Cebuano women in the past were attached to rice pouch weaving known as puso. But, these aforementioned domestications of women thwart the expression of rights domination afforded to women in history. Their humanity is being dragged as inferior compared to their male counterpart more especially to single mothers who have children out of wedlock are covered with restrictive social norms, who are displaced or discriminated in looking for employment (Bimbashi and Marsic, 2015).

As time changes, women start asserting their voices to be heard; demanding their rights to be respected; and their roles to be re-shifted. LGBT movement sprouts, expressing a more similar identity claim as one of the most vulnerable members of society, to reassert their respective rights to co-exist, at par with the recognition of men's rights. With more women are conscious about their oppressed rights to be recognized, equitability of the distribution and ownership of economic resources and equality in terms of human treatment are the noblest intention in a successful gender and development program implementation.

Women are becoming more important in the global marketplace not just as workers but also as consumers, entrepreneurs, managers, investors, and owners of business enterprises. Economists believe that if women are provided with equal opportunities, their economic participation will be maximized. If provided with the necessary support mechanisms, such as capital generation assistance, access to livelihood trainings, market, information, and technology, women can be more effective and efficient contributors to the national economy.

While, we see the Philippines ranks the $5^{\text {th }}$ country in the world that promotes the sensitivity to women, RA 9710 promotes the rights of Filipino women against other forms of discrimination and violence (Saludes, 2015). In the province of Cebu, the Code of Women in Cebu is enacted to recognize protection of the rights of women under Board Resolution Number 4236-2005 (Mojares, 1997) and (Bentillo, Cortes, Gabor, Navarrete, and Inocian, 2015). Cebuano women deserve to be 
documented and recognized not just the illustrious trailblazers in education, arts, heritage conservation, and in business; but special lens to focus on the lives of women in peripheral corners of society known as the women trisikad drivers. As the main hub and the most important center of commerce, trade, and industry in the Visayaas, Cebu city raises a group of women in the segment of her urbanite society, women drive trisikad (trishaw) to augment their way of living, in a most tacit way.

In Cebuano term the word "sikad" means 'to kick on', a basic skill in biking using a pedal, an essential skill in driving a trisikad. This means of a non-motorized vehicle is one of the popular short-distance vehicles on land. It addresses the mobility requirement of the people, delivering cargos and passengers' right their doorstep, with the use of one's brawn. Local tourists know that trisikad is one the economical short-distance ways to get around, that makes it more popularly use in almost all parts of the country's villages.

When the fuel crisis in the late 80s and early 90s causes untold sufferings to commuters, some entrepreneurs think of reviving a shortdistance transport vehicle dubs as trisikad in the early 60s. The sidecar of a trisikad can normally accommodate two passengers, unlike that of a motorized tricycle which can carry four averaged-sized passengers. This is a unique innovation of bicycle extended with a side cab utilized to ferry limited number of passengers in a short distance. This is commonly seen in crowded public villages where residents have no access to private transportation. These drivers are normally hired with 5.00 to 8.00 pesos per passenger before reaching to the main road where passengers can avail access to a public transport vehicle like a taxi or a jeep at the main road. The speed of a trisikad travel is directly proportional to the leg power of its driver, which means the faster the leg power to treadle, the faster is the driving. Trisikad driving is dependent with the health and energy of the driver.

Trisikad, like the tartanilla or horse-drawn carriage, can never be seen in the major streets of Cebu City because the government has banned them from these routes, but these can be seen in certain areas away from commercial districts, in order to prevent traffic congestions (Manugas, Recto, Sollano, Inocian, and Cabras, 2015). These small, crawling threewheeled trisikad are visible from sunrise to sunset, more in the narrow streets of a highly crowded ghetto, mostly driven by male drivers. But, because of the dire need of equitability in earning for additional income to sustain the basic necessities of the family, their wives resort to become trisikad drivers.

Despite the common expectations that men are driving a trisikad, an enumerable number of women are driving it in order to meet both ends 
meet for the family. They are found in Cebu city's urbanized metropolis. Acknowledging them is one way of recognizing the Filipino society to be gender sensitive. Though it is surprising to know how these women become trisikad drivers, thus, the intention of this study tries to document on how these women are driven to be actively involved in a male oriented means of living, without construing that their fate is a marginalization on their part as women.

\section{Related Literature}

In the study conducted by Women in Trucking, President and CEO Ellen Voie (2013), says that there are indications that female commercial drivers have more potential to be safer drivers on the road compared than male drivers. To prevent road accidents, female drivers are not that aggressive and riskier compared than their male counterparts. This is supported by Sivak (2015) that women drive less to have a lower tendency of committing fatal accidents on the road per distance. Women drivers contribute to road safety. Road safety is a global issue where drivers and pedestrians expect all states of the world to adapt efforts to ensure a high level of safety while driving (Herber, 2015).

In the Philippines, the aviation industry is now invaded by women pilots, though they are small in number, but they are steadily growing (rappler.com). On this website, year 2015 breaks a historic event of 25 aviatrixes or women pilots, who are now entering into the male dominated world of flying industry in the Philippines. This proves an indication of women empowerment in Philippine education, government, and industry.

There are lamentable stories about women drivers, Barandon (2015), one of the female drivers in Manila, acclaims that "passengers are happy when they see a female driver in a public utility vehicle, because a lady driver has moderate driving and honest”. She further adds that unlike the male drivers, lady drivers take care of their unit and make it clean for passengers' use. As such, Sabillo (2013) recommends breaking peoples' stereotypes on female drivers, because once they can learn as fast as of men in terms of the mechanical aspect which is normally the job of a male mechanic or machinist.

On the belief that women are easily stressed than men in terms of strenuous work, Solis and Lopez (2015) stress out that this is not true because on their study they found that "stress level has no significant effect on adversity quotient of single working mothers". This means that for the trisikad drivers, stress in driving daily is a manageable job. They venture the male dominated work because they always look forward on the welfare of their family. In fact, Karubi (2006), in Desoloc (2014), mentions that "many feminist and development practitioners have claimed that when women asked 
what they needed most to develop, they repeatedly answered income to provide for themselves and their children".

This mirrors a mother instinct tendency of most women workers that more than anything else about themselves the priority is their children in the family. Though, male dominated professions are now conquered and dominated by females in the field of the military, air and water navigation, construction and engineering, but their numbers are still limited to equate the roles and functions of men. The participation of women in labor can never be undervalued; the study of Abocejo, Pañares, Dotillos, Diones and Belciña (2012) recognizes the empowerment of women in microfinances, organizing and availing on the services of the cooperatives those benefits to alleviate poverty.

\section{Objectives of the Study}

The study determined the fantasies and aspirations of women trisikad drivers in Cebu City. Specifically, the study aimed to: determine the personal profile of women trisikad drivers in Cebu City, examine the factors that influence their lives as trisikad drivers, extrapolate lived experiences that promote women's decisiveness and access to economic resources.

\section{Research Methods and Materials Research Design}

The study utilized a case study design with narrative descriptions of the respondents' lived experiences. They were identified through a purposive sampling using the following criteria as women with: low level income, identified by village officials as trisikad drivers for more than ten years, and exhibited the age of maturity. With these criteria, 7 women trisikad drivers were sieved as the selected sample size, with three series of social encounter on the most convenient time identified by them. This study was conducted in Pasil, Cebu City specifically in Taboan and San Nicolas districts where a lot of women trisikad drivers were found.

\section{Research Tools}

To describe the fantasies and aspirations of women trisikad drivers, the researchers utilized Lloyd de Mause concept on fantasy analysis. Unstructured interview questions were constructed and then were validated by three social science experts. When respondents were interviewed, the body language, metaphors, repetitive phrases, similes, strong feelings and symbolic terms were jotted down, as field notes. These data were clustered and were coded, in order to determine metaphorical themes. 


\section{Results and Discussion}

\section{A Profile of Impoverished Life}

Respondents' age profile reveals that they belong to the age bracket between 34-55 years old, they are married with 2-6 children, and whose husbands are also trisikad drivers. They earn Php100.00-Php 200.00 (2 to 4 US \$) a day especially during Sundays, they start driving daily at 7 o'clock in the morning and end at 5 o'clock in the afternoon. These respondents' impoverished profile symbolizes a classic portrait of women in poverty in Philippine urban metropolis. This form of exploitation affects their health conditions because they can hardly maintain a decent meal and their bodies are exposed to the scorching heat of the sun. Based on the actual observation, this situation of women reflects a classic metaphor of starving like a rat in a highly competitive rat race society. In a rat race society, there is so much competition in terms of the acquisition of limited resources; people in poverty are disadvantaged because they do not own the resources. They starve like a rat, because they are seeking a little amount of money in order to meet both ends meet for survival. This is when women received low paying jobs compared to men and they still carry greater proportion of unpaid work (Masike, Mwanza and Masiyazi, 2014). This situation is even aggravated when disasters or natural calamities hit the Philippines, women are mostly affected. According to Niemeyer and Plumper (2007) in Iqbal, Baig, Sadia, Khurshed, and Saleem (2013), women are typically more vulnerable than men during natural disasters because of socioeconomic differences and inequitable power relations.

\section{Gender Assertive Fantasies}

While accepting their fate as being trisikad drivers from their husbands who fail to remit their income for the family's needs, they are proud that they can find other means to generate income, in order for the entire family to survive. It starts of a common fantasy if men can drive the trisikad, and then 'a what if imagery takes place' that "there is no reason that women cannot drive at the same way like their husbands do" (R1). This means that if there is a will to do there is always a way to perform. Gender equity (possession and ownership of resources or trisikad) and gender equality (parity of rights and opportunities to drive a trisikad) begin with the power to act. R2, R6, and R7 start lamenting that "to earn for the family squelches them the feeling of being empowered and taking control over economic resources". They feel like a superwoman that finds her way out at the end of the tunnel. However, R3 and R4 believe that by "driving trisikad is a breather because their husband praise them and occasionally stop hurting them verbally". Analyzing on this narrative, women trisikad drivers are blinded that social regard of their husband that is still tantamount 
to inflicting violence on their gender identity as a woman with dignity in the family. These women represent of a blooming lily under the 42 degrees heat of a tropical summer. Though sad; but these women continue to lure daily passengers for the entire family to eat three times a day (R1-R7). They are the mother hen protecting their chicks from the gliding skyline hawk.

\section{Life Changing Aspirations}

R2, R4, R5 and R6 have not "expected that their life turns and ends up as trisikad drivers, they expect to have their lives supported by their husbands with everything”. Not being desperate of what their married life has ended, dreaming to sustain life for their children is one of resilient attitudes that these women have exhibited. These women twist a Cinderella syndrome of chasing ice castles in the air that they have to live a queenly life once they get married. They understand the reality of life that they are their husbands' co-equal in terms of finding the means of living. They are the family's buoyant force that makes the boat sail to its final destination, with their husbands as the propeller. It is a life-changing aspiration that these women have proven their identity that they are not only good for making babies and an excellent home-maker, but they can fulfil a simple dream of providing life to children under their parental care, which most probably some irresponsible husbands aspire for their self-vested interests or narcissistic tendencies. They are the newly hibernated amphibians in a hostile ecosystem of gender identity awareness.

\section{Lived Experiences}

When asked, "How it feels to be a trisikad driver?” R1, R2, R5 and $\mathrm{R} 7$ respond that "it is really fun, a challenging experience, and rewarding means of living." These responses extol that despite a difficult life, they are altruistic to offer their life of being a wife and a mother for their children's welfare. Though, based on actual observation, they experience painful joy, while they are driving their trisikad under the scorching heat of the sun; but they remain happy about on their current situation. When asked, "How they were treated by fellow male trisikad drivers? The seven of them said that these guys show respect on them. This is a simple gesture of co-existence at work while driving on the road-a dwindling sign to stereotyping women. Seeing them racing on the road, they are like army of ants, bringing home the beacon, providing meal on the table. All the respondents utter in many times: "pinangga ko sa akong bana" (they are loved by their husbands). This proves that they are a co-equal in raising a family. Wives are still respected and honored by their husbands, despite minor imperfections. They serve as the winds beneath their husbands' wings. 


\section{Economic Status}

According to R1, R3, and R6, "earning for Php 100.00 a day is enough to buy National Food Authority (NFA) rice or low quality rice plus "ginamos" (salted-fermented fish lings) for the family". Vis-à-vis, this status has been sustainable for a day for a typical family of three. This reality is similar to a job of a kuchero (driver of a horse-drawn carriage-tartanilla), to undertake for the daily subsistence in a tartanilla driving in the same districts, where this study has been conducted (Manugas, et al., 2015). This means that both the trisikad and the tartanilla drivers receive an income below the minimum wage-an indication of poverty that both genders suffer since the colonial times. Though, it shows that the respondents are contented of their current situation, they are all vulnerable to other social pressures. They enjoy smoking as a way of life; instead of using their limited income to buy for palatable meals on the table. They are living like chickens in a scratching and pecking condition. They live on what they actually earn for the day in a typical subsistence level economy.

\section{Conclusion}

Life of women trisikad drivers was dedicated to support a family meal, being a co-equal with their husbands. Living an impoverished life 'starved like a rat' in order to meet both ends meet. Their assertive fantasies proved that they were normal individuals who felt like: 'a superwoman that finds her way out at the end of the tunnel', empowered and took control over scarce resources, 'a blooming lily under the 42 degrees heat of a tropical summer', struggled poverty, and 'a mother hen protecting their chicks from a gliding skyline hawk', raised an income for children's survival. Their lifechanging aspirations included: 'chasing ice castles in the air', never met the normal Cindrella life syndrome, 'buoyant force that makes the boat sail to its final destination, with their husbands as the propeller', gained support by their husbands, and 'newly hibernated amphibians in a hostile ecosystem', despised the strain of gender stereotyping. Their lived experiences characterized in 'painful joy' because of their minimal income, 'serving as army of ants', chased equally with their male counterparts just to bring food on the table, and 'being the winds beneath their husbands' wings', assured by their husbands' love and protection. Though, their economic status is a 'scratching and pecking condition', earned typically in day-to-day subsistence with hope.

\section{Recommendation}

Based on the findings and conclusion of the study, the following are the recommendations: trisikad women drivers in the identified districts in Cebu City will be given attention by the local government, welfare groups 
may look into the possibilities of uplifting the economic life of women trisikad drivers, and further research will be conducted on the survival mechanisms of the women trisikad drivers because of their vital assertiveness on the role of women.

\section{References:}

Abocejo, F. et. al. (2012). Microfinance lending program of cooperatives in cebu, Philippines: realities, benefits and women's participation. Cebu Normal University Journals of Higher Education, Special Issue on Poverty Alleviation, Cebu City, Philippines

Barandon, J. (2015). Women behind the wheel in drive for equality in the Philippines. Date Retrieved April 24, 2016. http://edition.cnn.com/2012/05/03/world/asia/philippines-women-driversjeepney/ Bentillo, M.P., Cortes, E.A., Gabor, J. C., Navarrete, F., and Inocian, R. (2015). A life dedicated to public service: the lady l story. Asia Pacific Journal of Multidisciplinary Research, Volume 4, No. 2, May 2016.

Bimbashi, LK and Marsic, S. (2015). Experiences of single mothers in the labour market: comparative study in albania and Bosnia Herzegovina. European Scientific Journal. Volume 11, No. 23.

Desoloc, M. (2014). Women empowerment and climate change adaptation in northern quezon. Asia Pacific Journal of Multidisciplinary Research, Volume 2 No. 5.

Herber, FR. (2015). Road safety in the Republic of Serbia. European Scientific Journal. Volume 9, No. 32.

Inocian, R. (2015). Lukay art in the philippines: cebu's pride and unique ritual identity. Scholar's press, Germany.

Iqbal, MJ, Baig, MS, Sadia, H., Khurshed, MB, and Saleem, S, (2013). Gender mainstreaming in to community based disaster risk management. European Scientific Journal. Volume 9, No. 32.

Manugas, R., Recto, M., Sollano, D.M., Inocian, R., and Cabras, R.L (2015). Tartanilla: a symbolism of cebuano transportation heritage. Asia Pacific Journal of Multidisciplinary Research, Volume 3, No. 5 Part I, December 2015.

Masike, R., Mwanza, B. and Masiyazi, L (2014). A gender sensitive framework to safety and health at work. European Scientific Journal. Volume 10, No. 11.

Mojares, R. (1997). Cebu: more than an island. Makati: Metro Manila: Ayala Foundation Inc.

Sabillo, K.A. (2013). Breaking the lady driver stereotype. Date Retrieved April 24, 2016. http://lifestyle.inquirer.net/131141/breaking-the-lady-driverstereotype 
Saludes, M. (2015). Philippine gender gap narrow but women leaders still needed. Date Retrieved April 24, 2016. http://www.rappler.com/move$\mathrm{ph} /$ issues/gender-issues/86131-government-women-leadership Sivak, M. (2015). Women drivers closing the mileage gap. Date Retrieved May 19, 2016. http://www.umtri.umich.edu/what-weredoing/news/women-drivers-closing-mileage-gap

Solis, DB and Lopez, E. (2015). Stress level and adversity quotient among single working mothers. Date Retrieved May 18, 2016 http://www.apjmr.com/wp-content/uploads/2016/04/APJMR-20153.5.3.09.pdf

Voie, E. (2013). Women commercial drivers \& safety. The National Academies of Sciences, Engineering and Medicine. Date Retrieved May 19, 2016. https://rns.trb.org/dproject.asp?n=35343

(2015). PH female pilots: small in number but steadily growing. Date Retrieved May 19, 2016 http://www.rappler.com/business/industries/171-aviation-tourism/99423caap-ph-female-pilots-increasing 